\title{
РОЛЬ ГОСУДАРСТВА В СТИМУЛИРОВАНИИ ИННОВАЦИЙ В РЕСПУБЛИКЕ БЕЛАРУСЬ
}

\author{
(c) 2018 Киевич Александр Владимирович \\ доктор экономическихнаук, профессор кафедры финансов \\ Полесский государственный университет \\ 225710, Республика Беларусь, г. Пинск, ул. Днепровской флотилии 23 \\ E-mail: a.v.kievich@yandex.ru \\ (c) 2018 Конончук Ирина Анатольевна \\ кандидат экономических наук, доцент кафедры финансов \\ Полесский государственный университет \\ 225710, Республика Беларусь, г. Пинск, ул. Днепровской флотилии 23 \\ E-mail:i_kononchuk@mail.ru

\section{(C) 2018 Пригодич Ирина Александровна} \\ кандидат экономических наук, ассистент кафедры финансов \\ Полесский государственный университет \\ 225710, Республика Беларусь, г. Пинск, ул. Днепровской флотилии 23 \\ E-mail: prigodich.ira@yandex.by
}

В статье анализируется влияние инновационного развития страны на качественный рост и благосостояние экономики; подчёркивается, что в условиях ограниченности государственных финансовых ресурсов на правительственном уровне Республики Беларусь активно применяются косвенные и иные методы стимулирования инновационной деятельности.

Ключевые слова: инновации, конкурентоспособность, финансирование, налоговые льготы, эффективность.

Обеспечение качественного роста и благосостояния экономики страны в условиях быстроизменяющихся внешних и внутренних факторов экономического роста возможно только благодаря стратегии инновационного развития. Появление новых производств, инновационных технологий управления, повышение эффективности традиционных секторов экономики на базе оптимизации всех производственно-организационных решений позволяет рассчитывать на высокую степень отдачи.

Республика Беларусь (РБ), выбравшая инновационный вектор развития, обосновано проводит активную государственную политику, инструменты и методы которой носят характер, стимулирующий инновационную активность в стране. Базисом реализации намеченной в стране программы развития, выступает нормативно-правовая база, регламентирующая выполнение заданных правительством РБ процессов. И на сегодня продолжительная и кропотливая работа над улучшением инвестиционного климата в РБ получила достаточно проработанную и целостную систему нормативных документов, ре- гулирующих инвестиционную сферу, драйвером которой выступают инновации. Действующее в стране законодательство полностью раскрывает правовые основы и механизм реализации намеченной в РБ программы инновационного развития.

Так же наличие институтов, способных оказывать помощь материально-технического, финансового, организационно-методического, информационного, консультационного и иного обеспечения деятельности субъектов хозяйствования, реализующих инновационный проект, даёт необходимый толчок. Учитывая потребность инновационной экономики, в РБ на 01.01.2018 г. осуществляют деятельность 14 научно-технологических парков, 9 центров трансфера технологий, действуют специальные фонды, разработаны правовые основы функционирования венчурных организаций. Основные усилия данных структур сосредоточены на содействии развития предпринимательства в научной, научно-технической, инновационной сферах, создание благоприятных условий для осуществления инновационной деятельности при обеспечении 
передачи новшеств из сферы их разработки в сферу практического использования, а также финансовой поддержки деятельности в сфере инноваций.

Здесь подчеркнём, что в значительной степени состояние инновационной деятельности зависит от величины её финансирования. В РБ затраты на научные исследования и разработки в абсолютном выражении ежегодно увеличиваются, однако не обеспечивают даже рекомендуемого европейскими экспертами минимального уровня. Задействовав средства бюджета, внешние государственные займы, кредиты, собственные средства юридических лиц и индивидуальных предпринимателей, иные источники в 2017 году такие затраты составили 0,59\% к ВВП, сократившись за последнюю десятилетку почти в два раза (в 2007 году - 0,96\% в ВВП). Структурно являясь наиболее активным инвестором, государство обеспечивает финансирование практически половины затрат, направляемых на научно-исследовательские цели (табл. 1).

По результатам прошлого года из бюджетов различных уровней было профинансировано 41,8\% всех внутренних затрат в области научных исследований и разработок. Несмотря на эти цифры, Беларусь занимает последнее место среди европейских стран по показателю доли расходов государственного сектора в ВВП - 0,19\% в 2017 году. Для сравнения данный показатель в Германии - 0,94\%, Дании - 0,97\%, Норвегии $-0,95 \%$, ближайшей Польше $-0,32 \%$, Украине $-0,23 \%$.

Учитывая целевые ориентиры государства, из республиканского бюджета осуществляется финансирование проектов, включённых в государственную программу инновационного развития РБ, а также мероприятий по организации и развитию субъектов инновационной инфраструктуры. Для усиления государственной поддержки в части финансирования инновацион- ных проектов и научно-технических программ в РБ созданы фонды специального назначения: Белорусский инновационный фонд, инновационные фонды и инвестиционные фонды. Государство, принимая прямое участие в поддержке инновационных проектов, заинтересовано в реализации наиболее перспективных и эффективных, поэтому выделение средств из централизованного и других специально созданных фондов осуществляется на возвратной, а в отдельных случаях на платной основе [2].

Усилению ответственности всех участников инновационного процесса, а также формированию рынка научно-технической продукции способствует необходимость коммерциализации результатов научно-технической деятельности, созданных полностью или частично за счёт бюджетных средств, средств государственных внебюджетных фондов, в предусмотренных законодательством формах: реализация товаров (работ, услуг), созданных в результате применения соответствующих разработок или использование таких результатов для собственных нужд; предоставление на возмездной основе другим лицам права на использование результатов научных исследований.

Ограничения бюджетного финансирования возможностями государственной казны смещают акценты в структуре инвестиций на корпоративный сектор и привлечение иностранных инвестиций [3]. В РБ доля собственных средств в структуре инновационных инвестиций увеличилась с 27,6\% в 2011 году до 31,7\% в 2017 году с одновременным увеличением роли средств иностранных инвесторов до 14,1\%. Этому способствовали ряд решений, направленных на обеспечение эффективного взаимодействия компонентов инновационной системы в рамках проводимой в стране инвестиционно-инновационной политики:

- передача субъектам инновационной дея-

Таблица 1. Состав и структура внутренних затрат на научные исследования и разработки в Республике Беларусь за 2011-2017 гг.

\begin{tabular}{|l|c|c|c|c|c|c|}
\hline \multicolumn{1}{|c|}{ Источник финансирования } & 2011 г. & 2013 г. & 2014 г. & 2015 г. & 2016 г. & 2017 г. \\
\hline Собственные средства & 27,6 & 25,4 & 22,4 & 19,1 & 24,6 & 31,7 \\
\hline Средства бюджета & 45,1 & 48,6 & 48,1 & 44,7 & 44,0 & 41,8 \\
\hline Средства внебюджетных фондов & 0,5 & 1,0 & 1,2 & 1,3 & 0,7 & 1,1 \\
\hline $\begin{array}{l}\text { Средства иностранных инвесторов, } \\
\text { в том числе иностранные кредиты и займы }\end{array}$ & 8,8 & 8,1 & 7,9 & 12,7 & 16,6 & 14,1 \\
\hline Средства других организаций & 18,0 & 16,9 & 20,4 & 22,2 & 14,1 & 11,3 \\
\hline Итого & 100 & 100 & 100 & 100 & 100 & 100 \\
\hline
\end{tabular}

Источник. Собственная разработка на основании [1] 
тельности имущественных прав на результаты интеллектуальной деятельности;

- осуществление государственных закупок в сфере инновационной деятельности;

- установление и выплату вознаграждения авторам инновации. Так, на законодательном уровне закреплено право получения автором инновации в течение 5 лет не менее 10\% годовой прибыли, полученной организациями за использование результатов исследовательских работ;

- проводимая денежно-кредитная и бюджетно-налоговая политика, стимулирующая инновационную активность в стране [4].

Значимость инноваций для экономического развития РБ предопределила и преференциальную систему налогообложения субъектов инновационной деятельности, производящих и реализующих инновационные продукты. Действующее налоговое законодательство РБ, нормативные правовые акты как республиканских, так и местных органов государственного управления содержит ряд льгот по НДС, налогу на прибыль, имущественным налогам и иным обязательным платежам в бюджет и внебюджетные фонды РБ.

Должное внимание особо уделяется предоставлению налоговых льгот по основному бюджетообразующему налогу - НДС. Учитывая важное фискальное значение НДС в обеспечении финансовой основы государства, а именно более 35\% всех налоговых поступлений консолидированного бюджета РБ (за 2017 год), государство, обеспечивая приоритетность направлений социально-экономического развития, предоставляет возможность применения освобождения от обложения НДС отдельных оборотов по реализации. С учётом положительной зарубежной практики предоставления льгот по НДС, освобождению, при соблюдении условия раздельного учёта соответствующих операций и распределения налоговых вычетов, относящихся к данным оборотам, методом раздельного учёта, подлежат обороты по реализации:

- научно-исследовательских, опытно-конструкторских, опытно-техно-логических работ, имеющих значение для реализации приоритетов социально-экономического развития, разработки новых технологических процессов, наукоемкой, конкурентоспособной продукции, формирования перспективных научных направлений, независимо от источников финансирования работ, которые выполняются организациями и индивидуальными предпринимателями на территории РБ;

- имущественных прав на изобретения, полезные модели, промышленные образцы, селекционные достижения, топологии интегральных микросхем, секреты производства (ноу-хау);

- имущественных прав на результаты научной и научно-технической деятельности, сведения о которых содержатся в государственном реестре прав на результаты научной и научно-технической деятельности, созданные полностью или частично за счёт государственных средств.

Однако справедливым будет отметить, что в условиях зачётного метода расчёта НДС освобождение от обложения приводит к росту затрат, увеличивает срок возврата инвестиционных ресурсов, а в условиях дорогостоящих кредитных ресурсов - это оборачивается значительными финансовыми потерями [5]. Превышение темпов роста объёмов научно-исследовательских работ над темпами роста расходов капитального характера выступает не в пользу данной льготы с позиций её стимулирующего назначения (табл. 2).

В условиях применения освобождения от обложения отдельных оборотов организация относит суммы НДС, выставленные поставщиками оборудования, машин, не на уменьшение НДС, подлежащего к перечислению в бюджет, а на увеличение затрат. В случаях превышения темпов роста расходов капитального характера над темпами роста оборотов по реализации (наблюдается в РБ в 2016-2017 годах) данная льгота нивелируется и снижается результативность с позиций рентабельности данного вида работ. Более оптимальным вариантом в данном случае видится возврат из бюджета сумм, уплаченных

Таблица 2. Темпы роста объемов выполненных научно- исследовательских работ и капитальных затрат в Республике Беларусь за 2013-2017 годы

\begin{tabular}{|l|l|l|l|l|l|}
\hline \multicolumn{1}{|c|}{ Показатель } & \multicolumn{1}{c|}{2013 г. } & \multicolumn{1}{c|}{2014 г. } & \multicolumn{1}{c|}{2015 г. } & \multicolumn{1}{c|}{2016 г. } & \multicolumn{1}{c|}{2017 г. } \\
\hline $\begin{array}{l}\text { Темп роста объема выполненных } \\
\text { научно-исследовательских работ }\end{array}$ & 164 & 136 & 109 & 109 & 122 \\
\hline Темп роста капитальных затрат & 22 & 74 & 52 & в 2,13 раза & в 2,43 раза \\
\hline
\end{tabular}

Источник:. Собственная разработка на основании [6] 
при приобретении облагаемой НДС продукции.

Учитывая стратегическое значение финансирования инновационных проектов за счёт государственных средств, их ограниченность и актуальность повышения эффективности такого вида государственной поддержки, при безвозмездной передаче имущества, при приобретении (ввозе) которого суммы налога на добавленную стоимость уплачены за счёт средств бюджета либо государственных внебюджетных фондов, объект обложения отсутствует, что вообще исключает необходимость отражения таких оборотов в налоговой декларации и упрощает налоговый учёт.

Так же первоочередной задачей государства, определившей для себя инновационный путь развития, выступает подготовка соответствующих высококвалифицированных кадров, реализация системы непрерывного образования. Согласно Отчёту о развития человечества, ежегодно публикуемого Программой развития $\mathrm{OOH}$, Республика Беларусь по индексу развития человеческого капитала, который учитывает кроме уровня жизни и долголетия, также грамотность и образованность населения, оценивается как страна с высоким значением данного показателя, занимая по данным исследования, проводившем в 2017 году, 52 место. Повышение доступности образования предполагает учёт ценового фактора потребления услуг не только высшего, но и послевузовского образования. Учитывая характерную особенность НДС как надбавки к цене, в целях снижения стоимости образовательных услуг обороты по их реализации освобождаются от обложения НДС (репетиторство, проведение репетиционного тестирования и др.).

Так же косвенным инструментом качественного изменения структуры профессорско-преподавательского состава, вовлеченного в процесс подготовки специалистов, в том числе высокотехнологичных производств, в сторону усиления роли кандидатов и докторов наук в данном направлении услуги, связанные с аттестацией научных работников высшей квалификации, присвоением учёных званий, нострификацией (приравниванием) документов о присуждении учёных степеней и присвоении учёных званий, выданных в иностранных государствах, переаттестацией лиц и др., оказываемые ВАК РБ, также включены в перечень освобождаемых от обложения НДС.

Развитию экспорта наукоёмкой продукции и технологий, увеличению их доли в общем объёме белорусского экспорта как качественного показателя инновационности белорусской экономики способствует применяемая по таким оборотам нулевая ставка НДС. Действующий подход в налогообложении в совокупности с другими способами обеспечили рост доли экспорта наукоёмкой и высокотехнологичной продукции в общем объёме экспорта с 30,9\% в 2015 году до 31,9\% в 2017 году. Кроме этого нулевая ставка НДС способствует развитию внешне-экономической деятельности как источника валютных поступлений в РБ, фактора максимизации прибыли и повышения рентабельности за счёт расширения географии поставок и международного разделения труда.

Реализация принципа «страны назначения» по косвенным налогам предполагает обложение НДС ввозимых на территорию РБ товаров. Применение зачётного метода расчёта НДС позволяет уменьшать сумму НДС, подлежащей перечислению в бюджет, на величину налога, уплаченного при ввозе. В силу данного обстоятельства предоставление освобождения от уплаты НДС при ввозе товара видится мнимой и неэффективной льготой с позиций стимулирования. Однако детальное изучение данного обстоятельства позволяет сделать вывод о том, что применение такого шага позволяет переместить во времени на более поздний период момент исполнения налогового обязательства, что в условиях дефицита оборотных средств субъектов хозяйствования выступает важным преимущественным фактором. Поэтому интересной с позиций оптимизации налогов и сборов видится льгота в виде освобождения от обложения НДС следующих товаров, ввозимых на таможенную территорию Республики Беларусь:

- оборудование, приборы, материалы и комплектующие изделия, предназначенные для выполнения научно-исследовательских, опытно-конструкторских и опытно-технологических работ;

- технологическое оборудование и запасные части к нему, предназначенные для реализации инвестиционных проектов, ввозимые резидентами Парка высоких технологий, Китайско-Белорусского индустриального парка «Великий камень»;

- семена, ввозимые для научных целей и государственного сортоиспытания.

Далее, как известно, ключевым компонентом налоговой системы государства выступает 
налогообложение прибыли. В условиях падения темпов экономического роста и борьбы за инвестора именно налогообложение прибыли может стать конкурентным преимуществом. Взятый РБ вектор на развитие инновационной экономики предполагает манипулирование конструктивными составляющими данного регулирующего налога и в рамках реализации налоговой политики активно используются такие факультативные элементы налога на прибыль, как льготы и вариантность формирования налогооблагаемой базы.

Важное стимулирующее значение имеет так же применение пониженных налоговых ставок при определении величины налога на прибыль. Так, научно-технологические парки, центры трансфера технологий при условии, что их деятельность соответствует направлениям деятельности, определённым для субъектов инновационной инфраструктуры, уплачивают налог на прибыль по ставке 10\% (вместо 18\%). Пониженная ставка в размере $10 \%$ применяется также в отношении прибыли, полученной от реализации товаров собственного производства, включённых в перечень высокотехнологичных товаров, определяемые как более конкурентоспособные и характеризующиеся более высокими технико-экономическими показателями по сравнению с другими товарами.

В случаях получения организацией прибыли от реализации высокотехнологичных товаров собственного производства при условии, что доля выручки от реализации таких товаров составляет более $50 \%$ общей суммы выручки субъекта хозяйствования, а также инновационных товаров при наличии сертификата собственного производства, плательщик вправе воспользоваться освобождением от обложения налогом на прибыль.

Эффективным инструментом, стимулирующим инвестиции в техническое совершенствование производства, внедрение новых технологий и инноваций является право отнесения на затраты, учитываемые при налогообложении прибыли, отдельных расходов, понесённых в процессе создания инновационных технологий, с применением повышающих коэффициентов. К таким относятся затраты на научно-исследовательские, опытно-конструкторские и опытно-технологические работы, зарегистрированные в государственном реестре в случае, если результатом их выполнения не стало создание амортизируемого имущества. Эти расходы могут учитываться при расчёте налогооблагаемой налогом на прибыль базы в размере, увеличенном на 50\% от фактически понесённых.

Существенные налоговые послабления явно ощущают на себе научно-технологические парки и научные организации в части уплаты земельного налога и налога на недвижимость. Поэтому предоставление льготы в виде освобождения от их уплаты до 1 января 2016 года, а затем до 1 января 2020 года выступает важным стимулирующим фактором.

Принимая во внимание экологизацию современной экономики РБ, без реализации которой невозможно обеспечить выпуск новой конкурентоспособной продукции, государство предоставило право уменьшать суммы налоговых платежей по экологическому налогу предприятиям, ориентированным на развитие экологической сертификации, переоснащение и реконструкцию пылегазоочистного оборудования, внедрение автоматизированных систем непрерывного контроля выбросов.

Важным составляющим платформы инновационного развития РБ, обеспечивающим не только рост конкурентоспособного экспорта, информатизацию общества и внедрение инновационных подходов взаимодействия государства, граждан и бизнеса, но и повышение эффективности базовых отраслей страны, является широкое применение информационно-коммуникационных технологий, инструментом развития которого выступают налоговые льготы. В этих целях юридическим лицам, производящим продукты программного обеспечения, разрабатывающим и осваивающим информационно-коммуникационные и другие прогрессивные технологии, предоставлена возможность зарегистрироваться в качестве резидентов Парка высоких технологий (ПВТ). Резиденты ПВТ имеют право на использование следующих преимуществ: полное освобождение от налога на прибыль, земельного налога, налога на недвижимость, налога на добавленную стоимость при реализации продукции на территории РБ и при ввозе товаров по импорту. Им уменьшаются размеры обязательных страховых взносов, ставки арендной платы, не взимаются таможенные пошлины. Опыт целенаправленного предоставления налоговых льгот подтвердил их высокую эффективность, как для субъектов хозяйствования, так и для государства в целом. В настоящее время около 90\% производимого в Парке программного обеспечения идёт на экс- 
порт в 50 стран мира, принося РБ валютные поступления, столь необходимые для регулирования платёжного баланса страны.

Реализация целевых программ, направленных на создание благоприятного климата для привлечения инвестиций и достижения высоких темпов технического прогресса в экономике также проявилась в форме создания Китайско-Белорусского индустриального парка (Парк), приоритетными областями деятельности которого являются: биомедицина, тонкая химия, электроника, машиностроение и новые материалы. Акцент делается на высокотехнологичные и конкурентоспособные производства, привлечение иностранных корпораций с известными мировыми брендами.

Резидентам Парка предоставлены огромные налоговые преференции, которые заключаются в освобождении в течение 10 лет от следующих платежей: налога на прибыль в отношении прибыли, полученной от реализации товаров (работ, услуг) собственного производства, произведенных на территории парка; налога на недвижимость по зданиям и сооружениям, расположенным на территории парка; земельного налога. В течение последующих 10 лет деятельности в парке резиденты уплачивают указанные налоги по ставкам, уменьшенным на 50\%.

Развитию свободных экономических зон в качестве площадок для организации производств, базирующихся на технологиях V и VI технологических укладов также способствует действующий льготный механизм налогообложения. Резиденты свободных экономических зон (СЭЗ) не обязаны уплачивать налог на прибыль в первые десять лет с момента её получения и освобождаются от уплаты налога на недвижимость по капитальным строениям, расположенным на территории СЭЗ. Резиденты СЭЗ налог на добавленную стоимость исчисляют по льготной ставке 10\%, при этом высвобожденные денежные сред- ства не облагаются налогом на прибыль.

Существенной проблемой для большинства действующих предприятий остаётся высокая степень старения основных фондов, которая достигает 40\%. Обновление, техническое перевооружение, реконструкция, модернизация производственных мощностей требует больших финансовых вложений, главным источником которых является прибыль. А проблема физического и морального износа производственных фондов потребовала введения инвестиционного вычета, стимулирующая роль которого заключается в том, что налогоплательщик имеет право стоимость новых зданий, сооружений, а также стоимость вложений в их реконструкцию включать в состав затрат по производству и реализации товаров, учитываемых при налогообложении (10\% вложенной суммы, а по машинам и оборудованию - не более $20 \%$ ).

Кроме того в сферу налогового стимулирования бизнеса входят также особые режимы налогообложения и Налоговый кодекс РБ представляет их широкий диапазон при наличии и соблюдении определенных критериев. Использование данных налоговых режимов предполагает упрощение налогового и бухгалтерского учёта, методики налогообложения [7].

Практическая ценность и результативность принятых на правительственном уровне решений налогового и неналогового характера оценивается достижением отдельных запланированных показателей программы инновационного развития РБ и их положительной тенденцией в условиях снижения заданных целевых индикативных значений (табл. 3.).

Удельный вес инновационной продукции в общем объёме отгружённой продукции увеличился с 13,9\% в 2014 году до 17,4\% в 2017 году при запланированном значении $14,5 \%$. Весомым достижением является также увеличение экспорта инновационной продукции - практически тре-

Таблица 3. Основные показатели инновационной деятельности организаций 2014-2017 гг.

\begin{tabular}{|c|c|c|c|c|c|c|c|c|}
\hline \multirow[b]{2}{*}{ Показатель } & \multicolumn{2}{|c|}{2014 г. } & \multicolumn{2}{|c|}{2015 г. } & \multicolumn{2}{|c|}{2016 г. } & \multicolumn{2}{|c|}{2017 г. } \\
\hline & $\begin{array}{c}\text { прог- } \\
\text { но3 }\end{array}$ & факт & $\begin{array}{c}\text { прог- } \\
\text { но3 }\end{array}$ & факт & $\begin{array}{c}\text { прог- } \\
\text { но3 }\end{array}$ & факт & $\begin{array}{c}\text { прог- } \\
\text { но3 }\end{array}$ & факт \\
\hline $\begin{array}{l}\text { Удельный вес инновационно-активных } \\
\text { организаций в общем числе организаций,\% }\end{array}$ & 29,12 & 20,90 & 30,50 & 19,60 & 20,0 & 20,4 & 21,5 & 21,0 \\
\hline $\begin{array}{l}\text { Удельный вес отгруженной инновационной } \\
\text { продукции в общем объеме отгруженной } \\
\text { продукции,\% }\end{array}$ & 19,30 & 13,90 & 20,0 & 13,10 & 13,6 & 16,3 & 14,5 & 17,4 \\
\hline $\begin{array}{l}\text { Доля экспорта инновационной продукции } \\
\text { в общем объеме белорусского экспорта,\% }\end{array}$ & 30,0 & 27,7 & 32,1 & 30,9 & 31,0 & 33,2 & 31,5 & 31,9 \\
\hline
\end{tabular}

Источник. Собственная разработка на основании [8] 
тью часть всего белорусского экспорта обеспечила инновационная составляющая $-31,9 \%$ в 2017 году против 27,7\% в 2014 году. Несмотря на постепенное увеличение с 2015 года доли инновационно-активных субъектов хозяйствования в их общей численности заданное целевое значение не достигнуто.

Комплексную оценку эффективности всех мероприятий, проводимых в рамках инновационной программы в РБ, можно определить, используя показатель, рассчитываемый по формуле:

$$
\mathrm{E}=\frac{1}{n} \times \sum_{i=1}^{n} \frac{\Pi_{\phi i}}{\Pi_{\Pi i}}
$$

где Е - показатель эффективности; $\mathrm{n}$ - количество сводных целевых показателей; П чение i-го сводного целевого показателя, фактически достигнутого; $\Pi_{\text {пі }}-$ плановое значение і-го сводного целевого показателя.

Значение показателя $(1,06)$ свидетельствует о высокой степени эффективности принятых ключевых направлений, механизмов и инструментов реализации намеченных целей и задач проводимой в РБ инновационной политики.

Таким образом, в РБ, выбравшей инновационный путь развития, создана достаточно разветвлённая инновационная система, включающая в себя множество элементов. В стране разработана нормативно-правовая база, регламентирующая инновационную деятельность. Учитывая прямую связь между развитой инновационной инфраструктурой и развитием экономического, научного потенциала государства, в РБ созданы и действуют научно-технологические парки, инновационные центры, центры трансфера технологий, бизнес-инкубаторы, информационные и маркетинговые центры, центры научно-технического творчества молодежи, созданы венчурные организации.

Поиск продуктивных решений, направленных на стимулирование внедрения и использования инноваций с целью повышения конкурентоспособности белорусской экономики, доказало необходимость государственной поддержки данного флагмана экономического роста с использованием различных инструментов налогового и неналогового характера.

Принимая прямое участие в поддержке инновационных проектов, государство обеспечивает финансирование практически половины всех потребляемых ресурсов по заданным направлениям инновационного развития РБ. Анализ достигнутых показателей, определённых в качестве результирующих для оценки проводимой в стране инновационной политики, позволяет свидетельствовать о её эффективности.

\section{Библиографический список}

1. Наука и инновационная деятельность в Республике Беларусь = Science and innovation activity in the Republic of Belarus: стат. ежегодник, 2018 / Нац. стат. ком. Респ. Беларусь; [редкол.: И.В. Медведева (пред.) и др.].Минск, 2018.- 136 с.

2. Киевич А.В. Денежно-кредитная политика: рестрикция и экспансия в переходный период / А.В. Киевич, И.А. Конончук, И.А. Пригодич // Економічний форум. 2018. № 2. С. 290-297.

3. Киевич А.В. Главная причина - сам механизм глобального экономического кризиса: монография / А.В. Киевич.-Санкт-Петербург: «Инфо-да», 2012.-236 с.

4. Налоговый кодекс Республики Беларусь (Особенная часть): Кодекс Респ. Беларусь, 29 дек. 2009 г., № 71-3: принят Палатой представителей 11 дек. 2009 г.: одобр. Советом Респ. 18 дек. 2009 г.: в ред. Закона Респ. Беларусь от 09.01.2017 г. // Консультант Плюс: Беларусь. Технология 3000 [Электронный ресурс] / ООО «ЮрСпектр», Нац. центр правовой информ. Респ. Беларусь.- Минск, 2018.

5. Пригодич И.А. Ключевые аспекты ранней диагностики рисков в банках и пути её совершенствования // Экономика и банки. 2014. № 2. С. 26-33.

6. Кисель И.А. Особенности применяемых организациями Республики Беларусь методов налогового планирования // Вестник ПГУ. 2012. № 5. с.69-73.

7. Пригоди, И.А. Развитие интегрированной системы диагностики банковских рисков как актуальное направление совершенствования диагностики в банках // Экономический и бюллетень Научно-исс ледовательского института Министерства экономики Республики Беларусь. 2014. № 9. С. 28-35.

8. Конончук И.А. Освобождене от налогообложения в условиях зачетного метода расчета НДС / И.А. Конончук // Экономика и банки: научно-практический журнал. 2018. № 1. С. 19-24. 